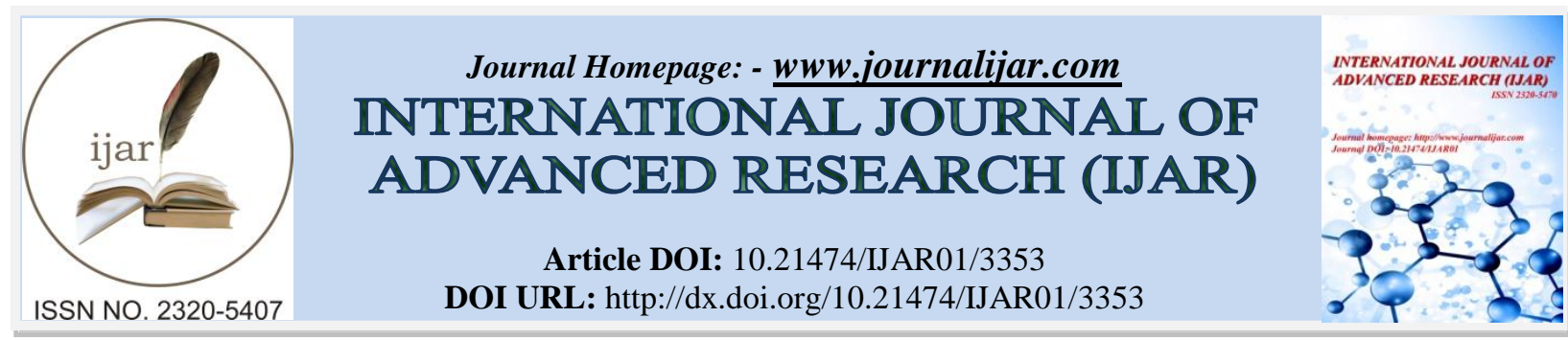

RESEARCH ARTICLE

\title{
INFLUENCE OF DIELECTRIC CONSTANT ON PROTONATION EQUILIBRIA OF MERCAPTOSUCCINIC ACID, L-DOPA AND 1, 10-PHENANTHROLINE IN AQUEOUS SOLUTIONS OF DIMETHYLFORMAMIDE
}

Aditya Deepthi D, Prasanthi J, and Nageswara Rao G*

School of Chemistry, Andhra University, Visakhapatnam, India.

\section{Manuscript Info}

Manuscript History

Received: 28 December 2016

Final Accepted: 20 January 2017

Published: February 2017

Key words:-

Mercaptosuccinic acid, 1, 10-

phenanthroline, L-

dopa,dimethylformamide, dielectric

constant, protonation constants.

\begin{abstract}
The protonation constant values of mercaptosuccinic acid, L-dopa and 1,10 -phenanthroline were determined in dimethylformamide (0$60 \% \mathrm{v} / \mathrm{v}$ ) at $303.0 \mathrm{~K}$ at ionic strength of $0.16 \mathrm{~mol} \mathrm{~L}^{-1}$ using $\mathrm{pH}$-metric technique. The protonation constants were calculated with the computer program MINIQUAD75 and selection of the best fit models was based on the statistical parameters. The $\log \mathrm{K}$ values were found to increase of the organic solvent content. The linear variations of the protonation constants with the reciprocal of the dielectric constant of the medium have been attributed to the dominance of electrostatic forces. Distribution of species, protonation equilibria and effect of influential parameters on the protonation constants have also been presented.
\end{abstract}

Copy Right, IJAR, 2017,. All rights reserved.

\section{Introduction:-}

Mercaptosuccinic acid (MSA) or thiomalic acid (HOOC-CH $\left.(\mathrm{SH})-\mathrm{CH}_{2}-\mathrm{COOH}\right)$ is a dicarboxylic acid containing a thiol functional group (-SH group) instead of an - $\mathrm{OH}$ group in malic acid [1]. It is also used as a building block in the synthesis of novel polyanionic inhibitors of human immunodeficiency virus and other viruses [2], and as a starting material in the synthesis of isocysteine, an important non-proteinogenic aminoacid in a potent peptide inhibitor of stromelysin [3]. In addition, sodium salt of the anionic Au (I) complex of 2-mercaptosuccinic acid is an effective anti-arthritic drug [4-9]. MSA is widely applied in industry and technology as corrosion inhibitor, electrolyte for electroplating bath, and components of bleach-fixing baths for photographic films and as an active material for depilatories and hair strengthening [10]. L-dopa (L-3, 4-dihydroxyphenylalanine) is a naturally occurring dietary supplement and psychoactive drug found in certain kinds of food and herbs, and is synthesized from the essential precursor to the neurotransmitters dopamine, norepinephrine (noradrenalin) and epinephrine (adrenaline). Dopa is used as pro-drug to increase dopamine levels in the treatment of Parkinsons disease [11, 12], since it is able to cross the blood-brain barrier whereas dopamine itself cannot. 1, 10-Phenanthroline (phen) is an organic compound. It is a bi-dentate ligand in coordination chemistry, it forms strong complexes with many metal ions. Phen, an N-donor ligand with planar aromatic rings is known [13-19] to form protonated species in acidic solution .i.e., $\mathrm{H}$ (phen) ${ }^{+}$and $\mathrm{H}(\mathrm{phen})^{2+}$ in the $\mathrm{pH}$ range of 2.0-9.0, and $\mathrm{H}_{2}(\mathrm{phen})^{2+}$ at $[\mathrm{H}+]>1 \mathrm{~mol} \mathrm{dm}^{-3}$. Due to hydrophobicity of aromatic rings in phen, the solubility of the neutral species is low in water which remarkably increases in organic solvents and also in aqua-organic mixtures.

In this paper, the protonation constants of mercaptosuccinic acid, dopa and phen[20] have been determined $\mathrm{pH}$ metrically in aqueous solutions of dimethylformamide ( $\mathrm{dmf}$ ) which is a common solvent for chemical reactions. 


\title{
Experimental:-
}

\section{Chemicals and Standard Solutions:-}

All the chemicals used in this investigation were of Analytical Reagent grade purity. Triple-distilled deionised water was used for the preparation of all the solutions. $0.05 \mathrm{M}$ solution of mercaptosuccinic acid (Himedia), L-dopa (Himedia), 1, 10-phenanthroline (Merck, Germany) was prepared by maintaining $0.05 \mathrm{M}$ nitric acid concentration to increase the solubility. Dimethylformamide (Merck, Germany) was used as received. $0.2 \mathrm{M}$ nitric acid solution was prepared. 2.0 M sodium nitrate (Merck, Germany) was prepared to maintain the ionic strength in the titrand. $0.4 \mathrm{M}$ sodium nitrate (Merck, Germany) was used as titrant. The acid and base solutions were standardized by standard methods. Thus, the concentration of the alkali was determined by titrating it with the standard oxalic acid and potassium hydrogen phthalate solutions, while the normality of nitric acid was determined using standardized sodium hydroxide and the primary standard borax solutions. In assessing the errors analysis of variance of one way classification (ANOVA) using the computer program COST [21]. The concentration of the carbonate-free sodium hydroxide solution was determined by titrating it against nitric acid solution using the gran plot method [22].

\begin{abstract}
Alkalimetric Titrations:-
The $\mathrm{pH}$ measurements proton-ligand system were carried out in the aqueous media containing varying compositions of organic solvent (dmf) in the $\mathrm{pH}$ range of $0-60 \% \mathrm{v} / \mathrm{v}$ maintaining an ionic strength of $0.16 \mathrm{M}$ with sodium nitrate at $303.0 \pm 0.1 \mathrm{~K}$ using a digital $\mathrm{pH}$ meter ELICO(readability 0.01 ) with mechanical stirring carried by a teflon stirrer. The glass electrode was equilibrated in a well stirred dmf-water mixtures containing alkali to check the complete equilibration of the glass electrode. The calomel electrode was refilled with $\mathrm{dmf}$-water mixtures periodically. Potassium hydrogen phthalate $(0.05 \mathrm{M})$ and borax $(0.01 \mathrm{M})$ solutions were used to calibrate the $\mathrm{pH}$ meter. In each titration, the titrand consisted of approximately $1 \mathrm{mmol}$ of nitric acid in a total volume of $50 \mathrm{ml}$.The amounts of MSA, L-dopa, phen in the titrands ranged between 0.25 and $0.375,0.50$ mmols. The glass electrode was equilibrated in a well stirred organic solvent-water mixture containing inert electrolyte for several days .At regular intervals, the strong acid was titrated against alkali to check the complete equilibration of the glass electrode. The details of the experimental procedure and titration assembly used in our laboratory have been given elsewhere [23].
\end{abstract}

\section{Results and Discussion:- \\ Best fit Model:-}

The computer program SCPHD [24] was used to calculate the correction factor applied to $\mathrm{pH}$ meter dial reading to calculate approximate protonation constants of mercaptosuccinic acid, L-Dopa, and 1,10-phenanthroline. The best fit chemical model for each system investigated was arrived at using non-linear least-squares method in the initial refinement and reliable convergence of Marquardt algorithm [25]. The variation of stepwise constants was analyzed mainly on electrostatic grounds on the basis of solute-solute and solute-solvent interactions. The results of best fit models that contain the type of species and overall protonation constants of MSA, dopa, phen along with some important statistical parameters are given in Table 1. A low standard deviation in $\log \beta$ indicates the precision of these parameters. The small values of $U_{\text {corr" }}$ (the sum of the squares of deviations in concentrations of ligand and hydrogen ion at all experimental points) corrected for degrees of freedom, indicate that the experimental data can be represented by the model. Small values of mean, standard deviation and mean deviation for the system confirm that the residuals are around a zero mean with little dispersion.

For an ideal normal distribution, the values of kurtosis and skewness should be three and zero, respectively. The kurtosis values in the present study indicate that the residuals form leptokurtic patterns. The values of skewness recorded in the table are between -1.66 and 1.14. These data evince that the residuals form part of a normal distribution; hence, least squares method can be applied to the present data. The sufficiency of the model is further evident from the low crystallographic $\mathrm{R}$ values. Thus, the statistical parameters show that best fit models represent the acid base equilibria of MSA, dopa, phen in dmf-water mixtures. The primary alkalimetric titration data were stimulated and compared with the experimental alkalimetric titration data, to verify the sufficiency of the model. The overlap of the typical experimental and simulated titrations data given in Figure 1 indicates that the proposed models correctly represent the experimental data collected from the refinements carried in the pH range of 2.0-12.0.

\section{Effect of systematic errors on best fit model:-}

Any variation in the corrections of ingredients like alkali, mineral acid and the ligand effects the magnitude of protonation constants. Such parameters are termed influential parameters.MINIQUAD75 does not have provision to study the effect of systematic errors in the influential parameters on the magnitude of protonation constant. In order 
to rely upon the best fit chemical model for critical evaluation and application under varied experimental conditions with different accuracies of data acquisition, an investigation was made by introducing pessimistic errors in the concentrations of mineral acid, alkali, and ligand. The results of a typical system given in Table 2, emphasize that the errors in the concentrations of alkali and mineral acid affect the protonation constants with increased errors in the concentrations of the ingredients corroborate the appropriateness of the experimental conditions. Statistically the best chemical models that represent acid-base equilibria under study should have very low standard deviation in their protonation constant $(\log \beta)$ values that indicate the precision of the parameters. The increased standard deviation in protonation constants and even rejection of some species on introduction of errors confirms the correctness of the proposed models. This type of investigation is significant as the data acquisition was done under varied experimental conditions with different accuracies.

\section{Protonation Equilibria:-}

The stepwise protonation constants and number of equilibria can be determined from the secondary formation functions such as average number of protons bound per mole of ligand $(\mathrm{nH})$. The $\mathrm{pH}$ values at half integral of $\mathrm{nH}$ correspond to the protonation constants of the ligand and the number of half integrals in the $\mathrm{pH}$ range range of the study corresponds to the number of equilibria. Thus, three half integrals $(0.5,1.5$, and 2.5$)$ versus $\mathrm{pH}$ in the case of MSA [figure 2(b)] and of dopa [figure 4(b)] conform the presence of three protonation-deprotonation equilibria. The maximum value of MSA and dopa in the formation curve figure 2(b) and 4(b) is three, which clearly shows that MSA and dopa has three bound protons per molecule and the half integral (0.5) of phen [figure 6(b)] ,emphasize the presence of one protonation-deprotonation equilibria in the $\mathrm{pH}$ range of present study.

The typical distribution plots figure [2(a),4(a),6(a)] produced using protonation constants from the best fit table 1, show the existence of $\mathrm{LH}_{3}, \mathrm{LH}_{2}, \mathrm{LH}$ and $\mathrm{L}$ species in case of MSA and $\mathrm{LH}_{4}{ }^{+}, \mathrm{LH}_{3} \mathrm{LH}_{2}{ }^{-}$, and $\mathrm{LH}^{2-}$ in dopa and $\mathrm{LH}^{+}$in the case of phen. $\mathrm{LH}^{+}$is the most predominant species in the case of phen [figure 6(a)] at a pH 3.5-11.0 and $\mathrm{LH}$ in case of MSA [figure 2(a)] at pH 2.0-9.0 respectively, and of dopa [figure 4(a)] it is $\mathrm{LH}_{3}$ at a pH range of 2.0-11.0.

\section{Effect of Solvent:-}

The reaction medium is one of the most important influencing factors in determining the equilibrium constants. The solvent effect on protonation constants could be explained on the basis of dielectric constant of the medium, solvent structure, preferential salvation and microscopic parameters. The variation of protonation constants or change in free energy with the organic solvent content depends upon two factors; electrostatic one, which can be estimated by Borns equation and non electrostatic one, which includes specific solute solvent interactions. When the electrostatic effects dominate the equilibrium proceeds, according to Borns equation [26], the energy of electrostatic interaction is related inversely to dielectric constant [27]. Hence, the logarithm of stepwise protonation constants $(\log K)$ should vary linearly as a function of the reciprocal of the dielectric constant of the medium. It is observed that in DMF media the $\log \mathrm{K}$ values of MSA, dopa and phen increase linearly as a content of organic containing pure water as a solvent [28-31] but small differences are possibly due to the different experimental procedures,temperature and different background electrolytes used. In this study the linear variation of $\log \mathrm{K}$ values as a function of 1/D (figure 8) in mixtures shows that the dominance of electrostatic interactions. This linear increase can be attributed to ion association reaction, solute solvent interactions and solvent basicity (acidity) effects. 
Table 1:- Best fit chemical model of protonation equilibria of $L$ - dopa, mercaptosuccinic acid and 1,10phenenanthroline in 0-60\% DMF - water mixtures.

Temperature 303.0K and ionic strength $0.16 \mathrm{~mol} \mathrm{~L}^{-1}$

\begin{tabular}{|c|c|c|c|c|c|c|c|c|c|c|}
\hline \multirow{2}{*}{$\begin{array}{l}\% \mathrm{v} / \mathrm{v} \\
\mathrm{DMF}\end{array}$} & \multicolumn{3}{|c|}{$\log \beta m l x h(S D)$} & \multirow[t]{2}{*}{ NP } & \multirow{2}{*}{$\begin{array}{r}\mathbf{U}_{\text {corr }} \\
\mathbf{X ~ 1 0}^{8} \\
\end{array}$} & \multirow[t]{2}{*}{ Skewness } & \multirow[t]{2}{*}{ Kurtosis } & \multirow[t]{2}{*}{$x^{2}$} & \multirow[t]{2}{*}{ R-Factor } & \multirow[t]{2}{*}{ pH range } \\
\hline & $\mathbf{L H}_{3}$ & $\mathbf{L H}_{2}$ & LH & & & & & & & \\
\hline \multicolumn{11}{|c|}{ L-dopa } \\
\hline 0.0 & $10.20(02)$ & $19.37(02)$ & $20.53(04)$ & 82 & 9.3 & -0.44 & 5.14 & 11.61 & 0.011347 & $\begin{array}{c}1.6-1.9 \\
8.49-10.5\end{array}$ \\
\hline 10 & $10.21(07)$ & $19.26(03)$ & $21.82(05)$ & 28 & 5.7 & 0.17 & 5.33 & 14.29 & 0.012959 & $\begin{array}{c}2.5-3.0 \\
9.5-10.00\end{array}$ \\
\hline 20 & $10.55(09)$ & $20.05(06)$ & $23.55(08)$ & 42 & 6.833 & 0.18 & 4.05 & 3.81 & 0.014946 & $\begin{array}{c}3.0-4.9 \\
8.9-10.0\end{array}$ \\
\hline 30 & $10.67(03)$ & $20.25(02)$ & $24.06(07)$ & 54 & 8.137 & 0.12 & 2.05 & 24.44 & 0.17293 & $\begin{array}{c}3.0-3.7 \\
8.4-10.5\end{array}$ \\
\hline 40 & $10.77(04)$ & $20.36(03)$ & $24.62(06)$ & 67 & 9.205 & 1.29 & 6.52 & 27.55 & 0.016183 & $\begin{array}{c}3.0-5.2 \\
8.5-10.5\end{array}$ \\
\hline 50 & $10.79(03)$ & $20.57(02)$ & $25.40(04)$ & 44 & 4.761 & 0.24 & 3.16 & 4.18 & 0.013365 & $\begin{array}{c}4.3-5.6 \\
9.4-10.5\end{array}$ \\
\hline 60 & $10.80(03)$ & $20.51(02)$ & $25.73(04)$ & 56 & 5.469 & 0.45 & 4.84 & 14.29 & 0.014436 & $\begin{array}{c}4.5-6.7 \\
8.8-10.5\end{array}$ \\
\hline \multicolumn{11}{|c|}{ Mercaptosuccinic acid } \\
\hline 0.0 & $9.97(04)$ & $14.35(05)$ & $17.16(06)$ & 87 & 42.70 & -0.09 & 4.27 & 28.11 & 0.021880 & $\begin{array}{l}2.5-3.1 \\
4.0-9.8 \\
\end{array}$ \\
\hline 10 & $10.08(02)$ & $14.49(04)$ & $17.27(08)$ & 66 & 14.66 & 0.86 & 6.31 & 15.52 & 0.029044 & $3.0-10.5$ \\
\hline 20 & $10.18(02)$ & $14.72(03)$ & $17.69(04)$ & 98 & 10.10 & $-2 . .45$ & 12.32 & 89.71 & 0.018642 & $\begin{array}{c}2.1-6.0 \\
9.0-11.0\end{array}$ \\
\hline 30 & $10.33(01)$ & $15.36(03)$ & $19.27(04)$ & 103 & 7.086 & 1.14 & 6.10 & 16.14 & 0.017858 & $3.1-11.5$ \\
\hline 40 & $10.47(04)$ & $15.57(08)$ & $19.35(09)$ & 70 & 41.19 & -0.07 & 3.14 & 21.49 & 0.042931 & $\begin{array}{c}3.5-9.5 \\
9.5-11.0\end{array}$ \\
\hline 50 & $10.54(04)$ & $16.31(07)$ & $20.98(08)$ & 80 & 40.21 & -0.89 & 6.18 & 9.20 & 0.042971 & $\begin{array}{c}4.3-7.5 \\
9.5-11.5\end{array}$ \\
\hline 60 & $10.81(04)$ & $17.12(08)$ & $22.43(09)$ & 69 & 45.83 & -1.66 & 11.48 & 9.01 & 0.041196 & $\begin{array}{c}4.75-6.9 \\
10.5-11.5\end{array}$ \\
\hline \multicolumn{11}{|c|}{ 1,10-phenanthroline } \\
\hline 0.0 & & & $4.92(02)$ & 21 & 14.881 & -0.39 & 2.78 & 3.71 & 0.042746 & $3.6-6.0$ \\
\hline 10 & & & $4.95(01)$ & 18 & 40.302 & -0.09 & 3.42 & 1.78 & 0.019978 & $3.5-5.0$ \\
\hline 20 & & & $4.98(03)$ & 19 & 24.404 & -0.7 & 2.82 & 11.26 & 0.054809 & $4.4-6.5$ \\
\hline 30 & & & $5.01(03)$ & 20 & 37.047 & -0.21 & 2.48 & 2.00 & 0.06992 & $4.6-6.0$ \\
\hline 40 & & & $5.06(03)$ & 20 & 31.488 & -0.56 & 2.83 & 3.26 & 0.061957 & $4.5-6.0$ \\
\hline 50 & & & $5.18(05)$ & 17 & 61.037 & -0.81 & 3.04 & 4.59 & 0.088476 & $4.8-6.0$ \\
\hline 60 & & & $5.24(07)$ & 12 & 90.34 & -0.86 & 3.11 & 6.67 & 0.102526 & $4.8-5.5$ \\
\hline
\end{tabular}

$\mathrm{U}_{\text {cor }}=\mathrm{U} /(\mathrm{NP}-\mathrm{m})^{*} 10^{8}$; where $\mathrm{m}$ is the no. of species and NP is number of experimental points , SD is the standard deviation. 
Table 2: Effect of errors in influential parameters on protonation constants of Mercaptosuccinic acid, dopa and1, 10- phenanthroline in $30 \% \mathrm{v} / \mathrm{v}$ DMF-water mixtures.

\begin{tabular}{|c|c|l|l|l|l|l|l|c|}
\hline Ingredient & $\begin{array}{c}\text { \% of } \\
\text { error }\end{array}$ & \multicolumn{2}{|c|}{ Mercaptosuccinic acid } & \multicolumn{3}{c|}{ L-Dopa } & $\begin{array}{c}\text { 1-10 } \\
\text { phenanthroline }\end{array}$ \\
\hline & & $\boldsymbol{\beta}_{\mathbf{1}}(\mathbf{S D})$ & $\boldsymbol{\beta}_{\mathbf{2}}(\mathbf{S D})$ & $\boldsymbol{\beta}_{\mathbf{3}}(\mathbf{S D})$ & $\boldsymbol{\beta}_{\mathbf{1}}(\mathbf{S D})$ & $\boldsymbol{\beta}_{\mathbf{2}}(\mathbf{S D})$ & $\boldsymbol{\beta}_{\mathbf{3}}(\mathbf{S D})$ & $\boldsymbol{\beta}_{\mathbf{1}}(\mathbf{S D})$ \\
\hline Alkali & 0 & $10.33(01)$ & $15.36(03)$ & $19.27(03)$ & $10.67(03)$ & $20.25(02)$ & $24.06(07)$ & $5.01(03)$ \\
\hline & -5 & $11.01(01)$ & $16.56(05)$ & $20.68(06)$ & $10.88(06)$ & $20.76(04)$ & $24.97(13)$ & $5.32(05)$ \\
\hline & -2 & $10.60(01)$ & $15.82(03)$ & $19.81(03)$ & $10.77(04)$ & $20.46(03)$ & $24.41(08)$ & $5.13(04)$ \\
\hline & 2 & $10.05(03)$ & $14.91(05)$ & $18.73(06)$ & $10.41(03)$ & $19.71(03)$ & $23.24(08)$ & $4.90(03)$ \\
\hline & 5 & $9.60(08)$ & $14.22(12)$ & $17.94(13)$ & $10.57(03)$ & $20.03(02)$ & $23.73(06)$ & $4.73(03)$ \\
\hline & & & & & & & & \\
\hline Acid & -5 & $9.93(03)$ & $14.68(03)$ & $18.38(07)$ & $10.51(03)$ & $19.82(03)$ & $23.27(08)$ & $4.69(03)$ \\
\hline & -2 & $10.17(02)$ & $15.09(04)$ & $18.91(04)$ & $10.61(03)$ & $20.085(02)$ & $23.74(07)$ & $4.88(03)$ \\
\hline & 2 & $10.48(01)$ & $15.63(03)$ & $19.62(03)$ & $10.78(06)$ & $20.63(03)$ & $25.01(19)$ & $5.15(04)$ \\
\hline & 5 & $10.70(02)$ & $16.04(04)$ & $20.15(05)$ & $10.73(04)$ & $20.41(02)$ & $24.40(09)$ & $5.36(06)$ \\
\hline & & & & & & & & \\
\hline Ligand & -5 & $10.01(03)$ & $14.89(06)$ & $18.80(06)$ & $10.57(03)$ & $20.13(02)$ & $24.03(09)$ & $5.06(04)$ \\
\hline & -2 & $10.20(02)$ & $15.18(03)$ & $19.08(03)$ & $10.63(03)$ & $20.20(02)$ & $24.05(08)$ & $5.03(04)$ \\
\hline & 2 & $10.44(01)$ & $15.54(02)$ & $19.44(02)$ & $10.77(04)$ & $20.37(03)$ & $24.10(06)$ & $4.99(03)$ \\
\hline & 5 & $10.61(01)$ & $15.80(02)$ & $19.71(02)$ & $10.71(04)$ & $20.30(02)$ & $24.08(07)$ & $4.97(03)$ \\
\hline
\end{tabular}
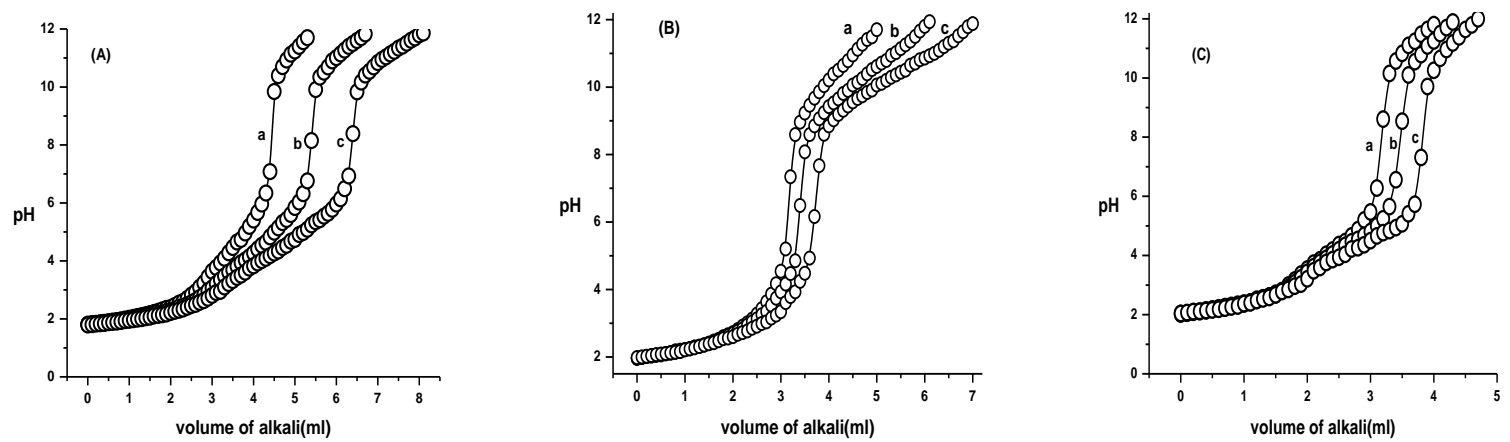

Figure 1:- simulated (o) and experimental (solid line) of (A) mercaptosuccinic acid (B) L-Dopa and (C) 1, 10phenanthroline in $30 \% \mathrm{v} / \mathrm{v}$ dimethylformamide : (a) 0.25 (b) 0.375 (c) $0.5 \mathrm{mmol}$,respectively.
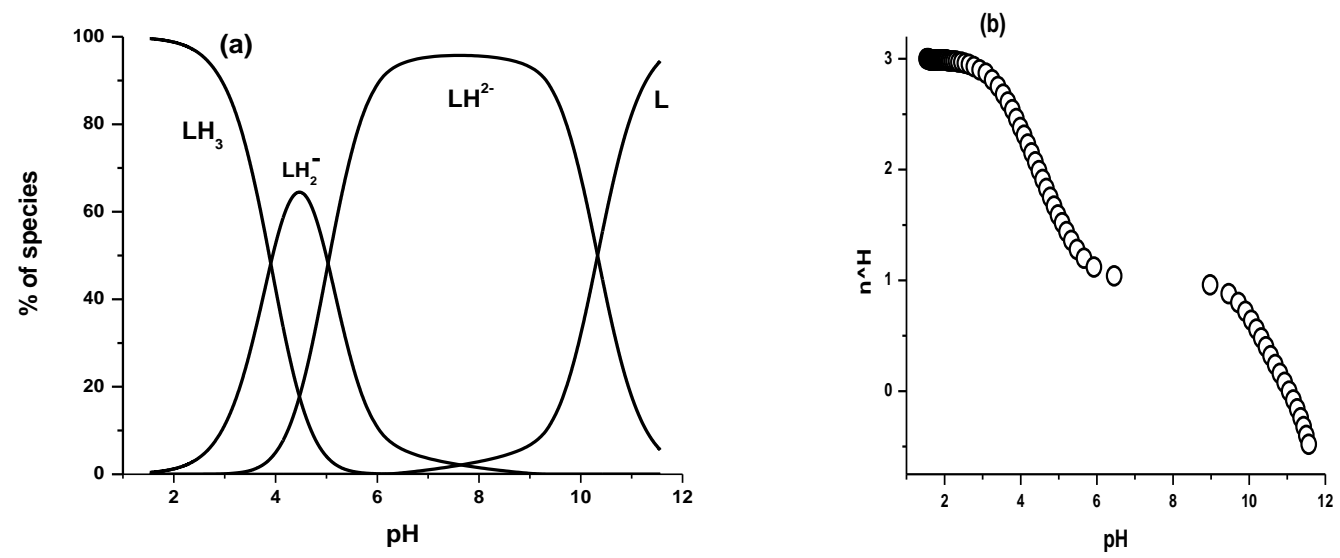

Figure 2:- (a) Distribution diagram of mercaptosuccinic acid and (b) formation function of mercaptosuccinic acid in $30 \% \mathrm{v} / \mathrm{v}$ in dmf-water mixture. 
<smiles>C=CC(C)OC(=O)C(S)CC(=O)OC(=O)C(S)CC(=O)OC(=O)C(S)CC(=O)O</smiles>

Figure 3:- Protonation - deprotonation equilibria of MSA
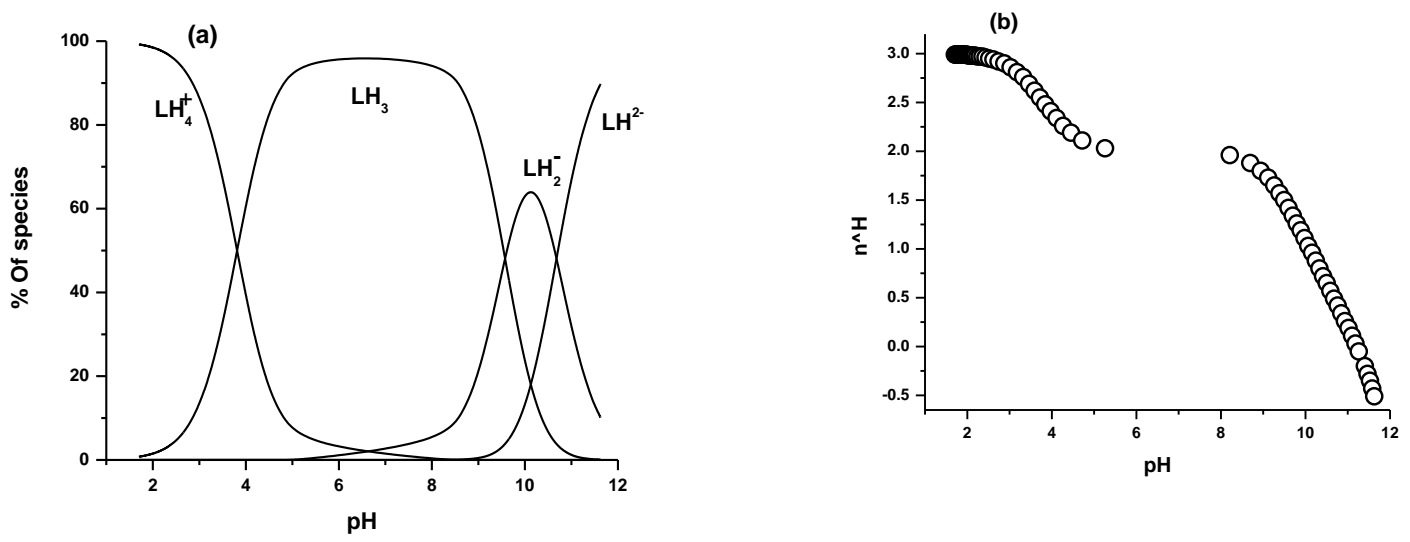

Figure 4:- (a) Distribution diagram of dopa and (b) formation function of dopa in 30\% v/v in DMF-water mixture

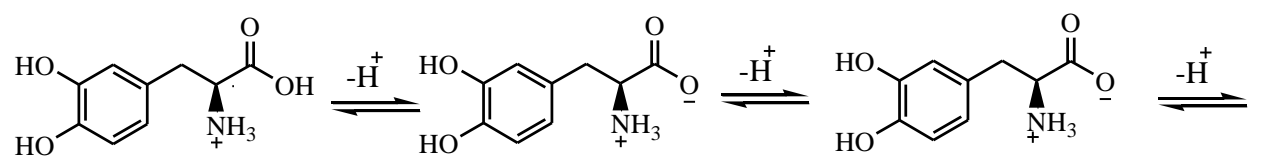<smiles>N[C@@H](Cc1ccc(O)c([O-])c1)C(=O)O</smiles>

$\mathrm{LH}_{4}^{+}$

$\mathrm{pH} \quad 2.0-8.0$
$\mathrm{LH}_{3}$

pH 2.0-11.0

(Zwitter ion)

Figure 5:- protonation -deprotonation equilibria of dopa 

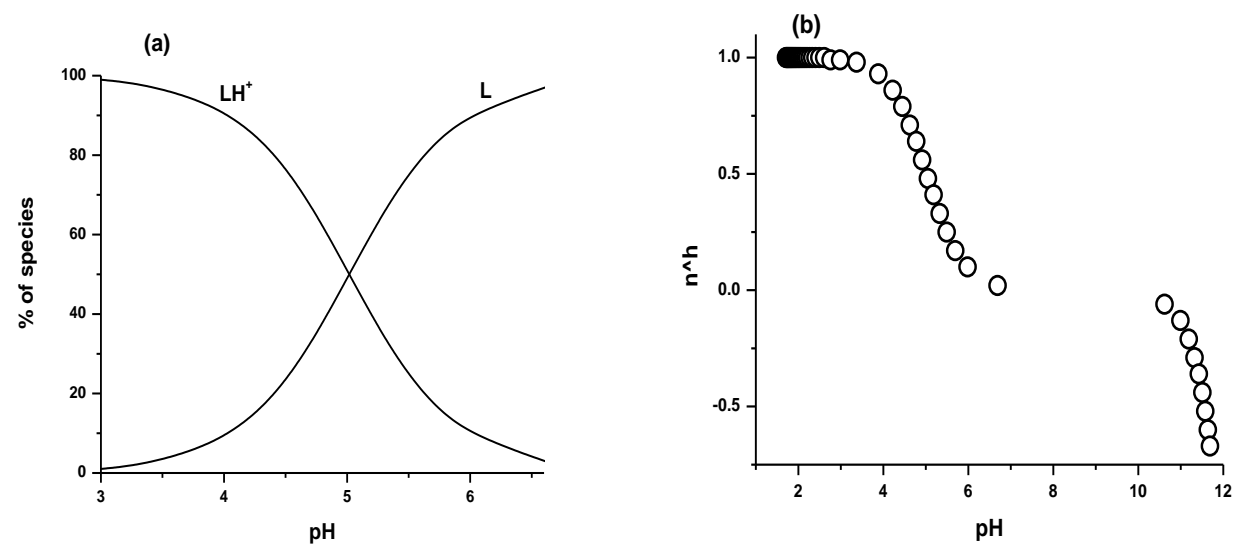

Figure 6:- (a) Distribution diagram and (b) formation function of phen in 30\% v/v in DMF-water mixture

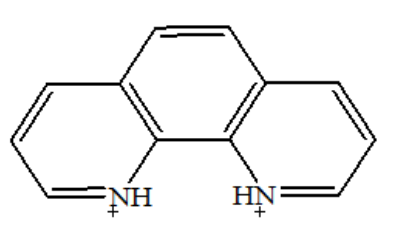

$\mathrm{LH}_{2}{ }^{+}$

$\mathrm{pH}<1$

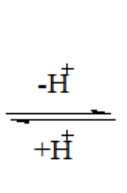<smiles>c1cnc2c(c1)ccc1ccc[nH+]c12</smiles>

$\mathrm{LH}^{+}$

$\mathrm{pH} \quad 2.0-9.0$

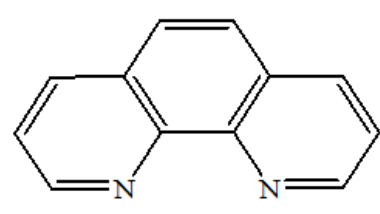

L

$\mathrm{pH} \quad 4.0-9.0$

Figure 7:- Protonation-deprotonation equilibria of phen
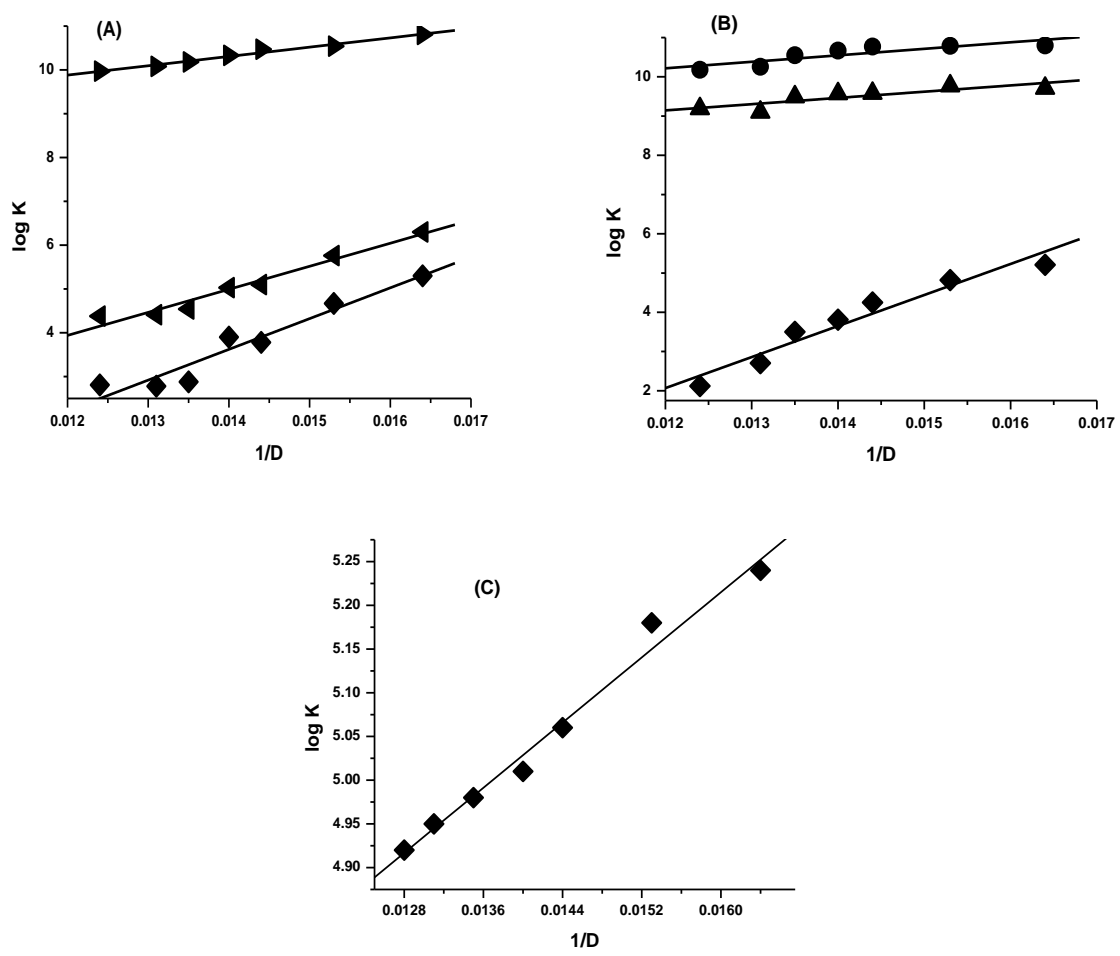

Figure 8:- variation of stepwise protonation constants (log K) of (A) MSA, (B) dopa and (C) phen with reciprocal of dielectric constant (1/D) in DMF medium. 


\section{Conclusions:-}

1. MSA has three dissociable protons which exists in $\mathrm{LH}_{3}$ form at low $\mathrm{pH}$ gets deprotonated with the formation of $\mathrm{LH}_{2}^{-}, \mathrm{LH}^{2-}$ and $\mathrm{L}^{3-}$ species successively, with increase in $\mathrm{pH}$.

2. Dopa has three dissociable protons and one amino group which can associate with a proton .It exists as $\mathrm{LH}^{4+}$ at low $\mathrm{pH}$ and gets deprotonated with the formation of $\mathrm{LH}_{3}, \mathrm{LH}_{2}{ }^{-}$and $\mathrm{LH}^{2-}$ successively with increase in $\mathrm{pH}$.

3. Phen forms $\mathrm{LH}_{2}$ at low $\mathrm{pH}$ and gets deprotonated with the formation of $\mathrm{LH}^{+}$and $\mathrm{L}^{2-}$ with increase in $\mathrm{pH}$.

4. The linear variation of log values of stepwise protonation constants with decreasing dielectric constant of the media confirms the dominance of electrostatic forces in the protonation-deprotonation equilibria of MSA.

5. The log values of protonation constants of dopa increase linearly with decreasing dielectric constant of dmfwater mixtures. This indicates the dominance of electrostatic forces in the protonation-deprotonation equilibria.

6. Phen exhibits linear trend indicating the dominance of electrostatic forces.

7. The effect of systematic errors in the influential parameters on the protonation constants shows that the errors in the concentrations of alkali and mineral acid affect the protonation constants more than those in the concentration of ligand solutions.

\section{Acknowledgements:-}

The author is grateful thank to UGC, New Delhi, for its financial support for this work and HOD, Dept. Of inorganic and analytical chemistry for helpful research facilities.

\section{References:-}

1. S. Patai, The Chemistry of the Thiol Group, Vol. 15, Wiley-Interscience, London, 1974 pp.569.

2. M. Rajopadhye, F. D. Popp, J. Heterocyclic Chem. 24, 1637, (1987)

3. B. S. Vashi, D. S. Mehta, V. H. Shah,Indian J. Chem. 34B, 802, (1995)

4. K. Desai, A. J. Baxi, J. Indian ChemSoc. 69, 212, (1992)

5. M. P. Dave, J. M. Patel, N. A. Langalia, K. A. Thaker, J. Indian Chem. Soc. 61, 891, (1984)

6. R. Pires, K. Burger, Tetrahedron Lett.37, 8159, (1996)

7. K. Nomiya, H. Yokoyama H. Nagano,M. Oda, S. Sakuma, Bull. Chem. Soc. Jpn. 68, 2875, (1995)

8. K. C. Dash, H. Schmidbaur, Metals Ions in Biological Systems, Vol. 14, H. Sigel eds. Marcel Dekker Inc., NewYork, USA, 1982; pp. 179

9. P. J. Sadler, Adv. Inorg. Chem. 36, 1, (1991)

10. A. Lorber, T. M. Simon, Gold Bull. 12, 149, (1979)

11. W. Birkmayer, O. Horneykiewicz, Wien. Klin. Wschr, 1961, 73, 787-788.

12. O. Horneykiewicz, Wien. Klin. Wschr, 1963, 75, 309-312.

13. M. J. Fahsel, C. V. Banks, J. Am.Chem. Soc., 1966, 88,878-884.

14. P. Paoletti, A. Dei, A. Vacca, J. Chem.Soc., (A), 1971, 2656-2659.

15. R. D. Alexander, A. W. L. Dudeney, R. J. Irving, J. Chem.Soc. Faraday Trans 1, 1978, 74, 1075-1080.

16. P. R. Mitchell, J. Chem. Soc. Dalton Trans., 1980, 1079-1086.

17. P. G. Daniele, C. Rigano, S. Sammartano, Talanta, 1985, 32, 78-80.

18. S. Capone, A. D. Robertis, C. D. Stefano, R. Scarcella, Talanta, 1985, 32, 675-677.

19. A. D. Robertis, C. Foti, A. Gianguzza, C. Rigano, J. Solution Chem., 1996, 25, 597-606.

20. S. Bandyopadhyay, A. K. Mandal, S.Aditya, J. Indian Chem. Soc., 1981, 58, 467-473.

21. R. S. Rao, G. N. Rao, Computer Applications in Chemistry,Himalaya Publishing House, Mumbai 2005, 302309.

22. G. Gran, Anal. Chim. Acta 206, 111,(1988)

23. M. P. Latha, V. M. Rao, T. S. Rao, G. N. Rao, Bull. Chem. Soc. Ethiop 21,363, (2007)

24. G. N. Rao Complex equilibria of some biologically important metal ions in Aqua - organic media, Ph. D.Thesis , Andhra University,Visakhapatnam, India 1989.

25. P. Gans, A. Sabatini, A. Vacca, Inorg. Chim. Acta 18, 237, (1976)

26. R. G. Bates, Determination of pH: Theory and Practice, J. Wiley \& Sons,Inc., NewYork,1964.

27. M. Born, Z. Phys. 45, 1, (1920)

28. A. P. Arnold, A. J. Canty, Can. J. Chem. 61, 1428, (1983)

29. G. R. Lenz, A. E. Martell, Inorg. Chem. 4, 378, (1965)

30. G. E. Cheney, Q. Fernando and H. Freiser, J. Phys. Chem. 63, 2055, (1959)

31. L. J. Perrin, D. D. Perrin, Aust. J. Chem. 22, 267, (1969) 